\title{
Where to place emergency ambulance vehicles? Using a capacitated maximum covering location model with real call data
}

Soheil Hashtarkhani

Mashhad University of Medical Sciences

Ping Yin

University of Mary Washington

Behzad Kiani

Mashhad University of Medical Sciences

Alireza Mohammadi

University of Mohaghegh Ardabili

Shahab MohammadEbrahimi

Mashhad University of Medical Sciences

Mahmood Tara ( $\sim$ Taram@mums.ac.ir)

Mashhad University of Medical Sciences

Stephen A. Matthews

The Pennsylvania State University

\section{Research Article}

Keywords: Location-allocation, Geographical information system, Resource management, Emergency medical service, Maximal coverage location problem

Posted Date: October 25th, 2021

DOI: https://doi.org/10.21203/rs.3.rs-994111/v1

License: (c) (1) This work is licensed under a Creative Commons Attribution 4.0 International License. Read Full License 


\section{Where to place emergency ambulance vehicles? Using a capacitated maximum covering location model with real call data}

Soheil Hashtarkhani ${ }^{1}$, Ping Yin ${ }^{2}$, Behzad Kiani ${ }^{3}$, Alireza Mohammadi ${ }^{4}$, Shahab MohammadEbrahimi ${ }^{5}$, Mahmood Tara ${ }^{6}$, Stephen A. Matthews ${ }^{7}$

1- Department of Medical Informatics, School of Medicine, Mashhad University of Medical Sciences, Mashhad, Iran (S.hashtarkhani@gmail.com) (ORCID: https://orcid.org/0000-0001-7750-6294)

2- Department of Geography, University of Mary Washington, Fredericksburg, Virginia, USA (pyin@umw.edu)

3- Department of Medical Informatics, School of Medicine, Mashhad University of Medical Sciences, Mashhad, Iran (Kiani.Behzad@gmail.com) (ORCID: https://orcid.org/0000-0002-8816-328X)

4- Department of Geography and Urban Planning, Faculty of Social Sciences, University of Mohaghegh Ardabili, Ardabil, Iran (AlirezaMohammadi20142014@gmail.com) (ORCID: https://orcid.org/00000002-3327-0942)

5- Department of Medical Informatics, School of Medicine, Mashhad University of Medical Sciences, Mashhad, Iran (shahabodd@gmail.com) (https://orcid.org/0000-0002-1494-1544)

6- Department of Medical Informatics, School of Medicine, Mashhad University of Medical Sciences, Mashhad, Iran (Taram@ mums.ac.ir) (https://orcid.org/0000-0003-3945-7772)

7- Department of Sociology and Criminology, and Department of Anthropology, The Pennsylvania State University, University Park, PA, USA (sxm27@ @su.edu) (https://0000-0002-1645-4854)

Corresponding author: Mahmood Tara, Department of Medical Informatics, School of Medicine, Mashhad University of Medical Sciences, Mashhad, Iran Email: Taram@mums.ac.ir

\section{Abstract}

Background: Timeliness of emergency medical services (EMS) is critical for patient survival. Identifying optimal locations for ambulance vehicles could increase the chance of timely service delivery. This study incorporates Geographical Information Systems (GIS) with a mathematical optimization technique to improve the 5-minute coverage of EMS demands.

Methods: This study was conducted in the county of Mashhad, the northeast of Iran, including 94 ambulance vehicles distributed across 74 EMS stations. Locations of demands were extracted using 
analysis of one-year EMS call data. Network analysis was employed to estimate the travel times. A maximal covering location problem (MCLP) model with a capacity threshold for vehicles was implemented using the CPLEX optimizer. To make the proposed model more practical in the context of EMS, we added a constraint to the model formulation to maintain an acceptable service level for all EMS calls. Two scenarios were implemented: (1) a relocation model of existing vehicles among existing stations and (2) an optimal allocation model of EMS vehicles and stations using a list of candidate locations.

Results: Using the relocation model, the proportion of calls for service within the 5-minute coverage standard increased from $69 \%$ to $75 \%$, ensuring all urban and rural service demands to be reached within 16 and 48 minutes, respectively. Our allocation model revealed that the coverage proportion could rise to $84 \%$ of the total call for service by adding ten vehicles and eight new stations.

Conclusions: Incorporating GIS techniques with optimization modeling has the potential to improve population health outcomes in real-world decision making regarding the accessibility and equity of health resource allocation including EMS services.

Keywords: Location-allocation, Geographical information system, Resource management, Emergency medical service, Maximal coverage location problem

\section{Introduction}

A foundational goal of Emergency Medical Services (EMS) is to provide timely and well-monitored care $(1,2)$. The patients' survival rate in pre-hospital care is mainly associated with response time; i.e., the time from call for service received to arrival at the scene of a medical emergency (3). In Iran, studies showed that more than $50 \%$ of those who have lost their lives in emergency events died at the scene and about $16 \%$ died on their way to the hospital (4). The geographical distribution of EMS facilities and ambulance vehicles plays an influential role in timely pre-hospital service delivery (5).

Geographical Information Systems (GIS) have continued to be used in the public health domain in a variety of applications. GIS and related spatial techniques have been used to analyze the spatial patterns of diseases, discover environmental risk factors, measure spatial service accessibility, and to 
manage health resources and services (6-9). In EMS setting, GIS provides a powerful tool to capture and analyze call for service data, call location, and responding vehicle locations (10). The call for service data contains timestamps such as the time when the call was received, the time when the call was assigned to an ambulance, the time when the ambulance departed, etc. (11). Using network analysis functionalities and online navigation tools, GIS plays a decision support role in selecting the best ambulance for a mission or optimum routing (12). GIS capabilities coupled with optimization modeling provide new tools for EMS planners to explore resource allocation (13).

Location-allocation problems deal with identifying optimal facility locations for addressing specific demands on service use (14). Due to the importance and sensitivity of the EMS setting, a large portion of the location-allocation literature is devoted to this domain (15). These location-allocation models are typically adopted from two types of classic models, the $\mathrm{p}$-median problems and the covering location problems. The $p$-median problem optimally locates $p$ facilities in order to minimize the travel time from the demands' location to their nearest facility (16). The covering location problems consider a demand point covered when receiving service from a facility within the specified threshold of travel time or distance (17). The location set covering model (LSCM) introduced by Toregas et al. (18) and the maximal covering location problem (MCLP) introduced by Church and ReVelle (19) have received considerable attention in the location covering literature (17). The objective of the LSCM is to find the minimum number of facilities and their locations to cover all of the demand points in a pre-defined standard (18). On the other hand, the MCLP aims to locate a fixed number of facilities to maximize the total demand covered by at least one facility (19). Each of these two covering models makes sense in their own context of viewpoint. The first is a planning tool to determine the appropriate number of vehicles needed to cover all service demands, while the second attempts to make the best possible use of all available resources (20).

A basic underlying assumption of the different versions of the MCLP model is that a facility can deliver service to unlimited service demands inside the coverage area. In reality, however, many service facilities have limited capacities to ensure an acceptable level of service. For example, an ambulance station can only respond to a limited number of demands because of the availability status of the vehicles at that station. Therefore, the capacity limit is a crucial consideration in location problems, 
especially for the setting of EMS facilities. Some studies indirectly solved the capacity concept using probabilistic modeling approaches (21-23). These models assign an unavailability probability to facilities that take into account the finite capacity of services in some way (24). Another approach, introduced by Current and Storbeck (25), is to develop the capacitated version of the MCLP which has been applied by researchers in various fields $(14,26-28)$. This model adds a maximum capacity constraint into the mathematical formulations of the MCLP to ensure that the demands allocated to a facility will not exceed the maximum capacity of that facility (28). However, the classic capacitated MCLP only considers the allocation of demands in the service coverage standard and ignores the other uncovered demands. This issue may be acceptable in many contexts, such as allocating retail stores, where the aim is to cover the maximum customers in a short time even by losing a portion of them (29). However, in settings that deal with emergency response and saving lives, every demand even in remote and low-population areas, must receive minimally acceptable care in a reasonable time. Accordingly, some researchers applied multi-objective functions to balance the accessibility of covered and uncovered demands $(27,30)$.

This study aimed to find the best locations for existing and new ambulance vehicles using a modified version of the capacitated MCLP. The objectives of the study were to 1) relocate existing vehicles optimally within the existing facilities and measuring the improved performance; and 2) allocate new vehicles in optimum locations, including existing and new candidate facility sites.

\section{Methods}

\subsection{Study area}

This study was conducted in Mashhad county, including Mashhad city, the capital of Razavi Khorasan Province, located in the northeast region of Iran. In 2016, Mashhad had an estimated population of almost 3.8 million, with over 3 million living within the urban areas (31). Mashhad is the second most populous city in Iran, and also the number-one tourist destination in the country; with over 20+ million visitors per annum (32). Mashhad county has one EMS call center, which dispatches ambulances for all urban and rural (or road) EMS service demands. 


\subsection{Data}

To perform a location-allocation model, three input datasets are necessary: a set of potential facilities to provide services; a set of demand points that consume them; and a cost matrix that shows the travel cost (e.g., drive time) from any pair of potential facility site and demand point (33). Using $\operatorname{ArcGIS}^{\mathrm{TM}}$ v.10.5.1, these components were prepared as follow:

\subsubsection{EMS facilities}

Mashhad county includes 94 ambulance vehicles distributed across 74 stations. Most of these resources are allocated to the urban area of Mashhad (79 ambulances in 59 stations). Figure 1 shows the study area and the current locations of the EMS stations. Each station includes one, two, or three ambulances.

In addition to the existing stations, 233 locations were selected among hospitals and public health facilities as candidate locations for establishing new EMS stations. Figure 2a shows the distribution of candidate locations in Mashhad county.

\subsubsection{Demand points}

We extracted 224,355 anonymized EMS request data from $1^{\text {st }}$ of Jun 2019 to $31^{\text {st }}$ of May 2020 from the EMS call center of Mashhad. All of the records contain the geographical location of emergency events in decimal degrees. To reduce the computational intensity while keeping high locational accuracy of demand in the location-allocation modeling, we created a grid network of polygons embracing the call for service points in the study area (Figure 1b). To this end, hexagonal grid polygons with an area of two square kilometers were used; an area equivalent to the average area of neighborhoods in Mashhad (9). After removing polygons with zero calls for service, 990 polygons remained out of 7,200 , with a minimum of one call and a maximum of 6,144 calls for service over the year (Figure 1b). Out of 990 demand polygons, 231 were in urban area and 759 in rural areas. Centroids of these 990 polygons were used as the location of demand points, while the number of calls within each polygon represented the demand weight. We have described the Spatio-temporal characteristics of the EMS callers in our recent research (in press). 


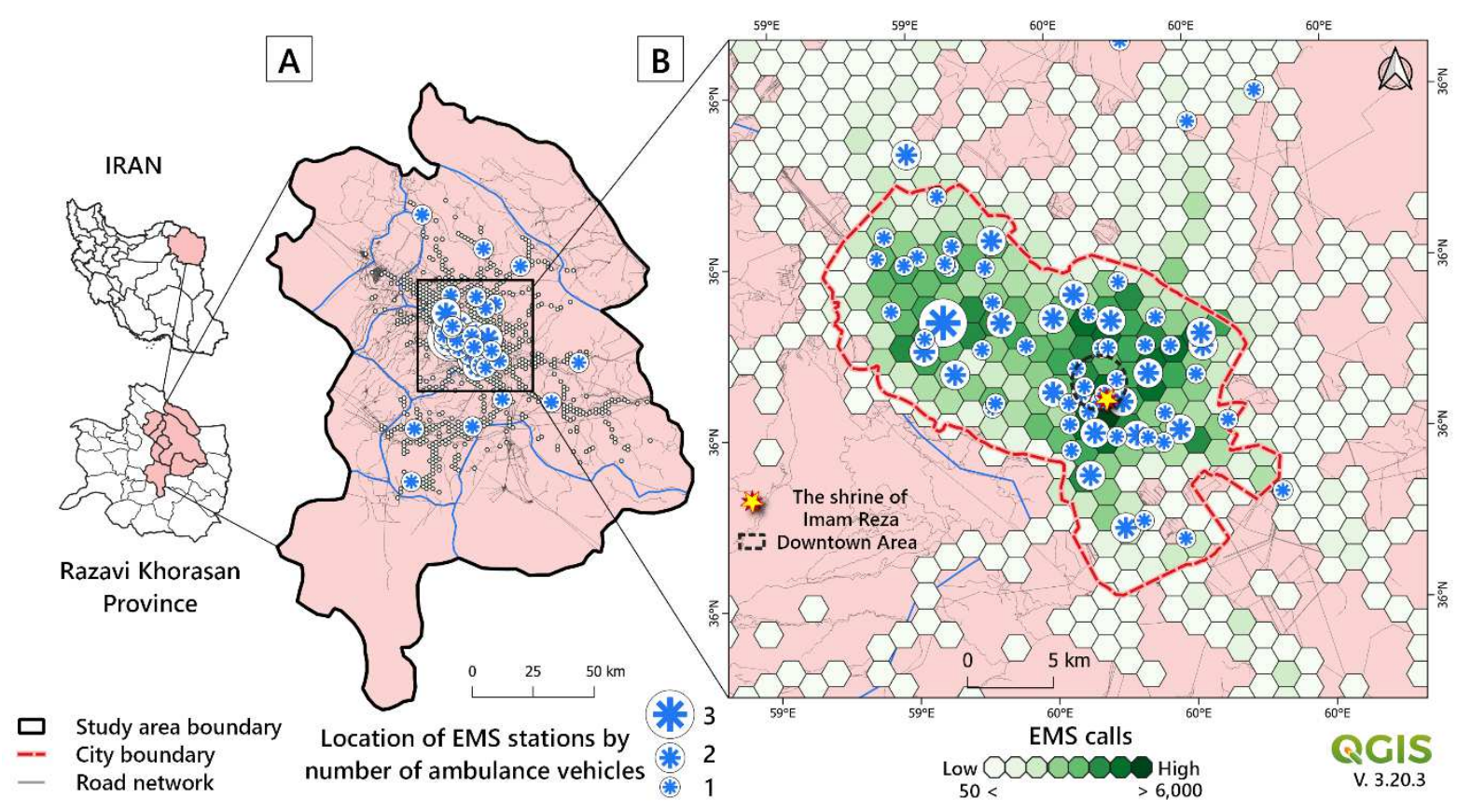

Figure 1: Distribution of existing stations and demand polygons a) whole study area b) urban area

\subsubsection{Cost Matrix}

Network distance was used to estimate the travel times of facility-to-demand routes. To this end, the digital road network of the study area was downloaded from the OpenStreetMap (OSM) database (34), a free and editable geographical database of the world. The OSM speed limits for Iran were used for different types of paths, including motorway, trunk, primary, secondary, tertiary, unclassified, and residential roads (35). Then the Origin-Destination cost matrix tool of $\operatorname{ArcGIS}^{\mathrm{TM}}$ v10.5.1 was used to create the cost matrix of travel times measured in minutes. Figure $2 b$ shows two examples of routing in the road network dataset as well as the estimated travel times. 


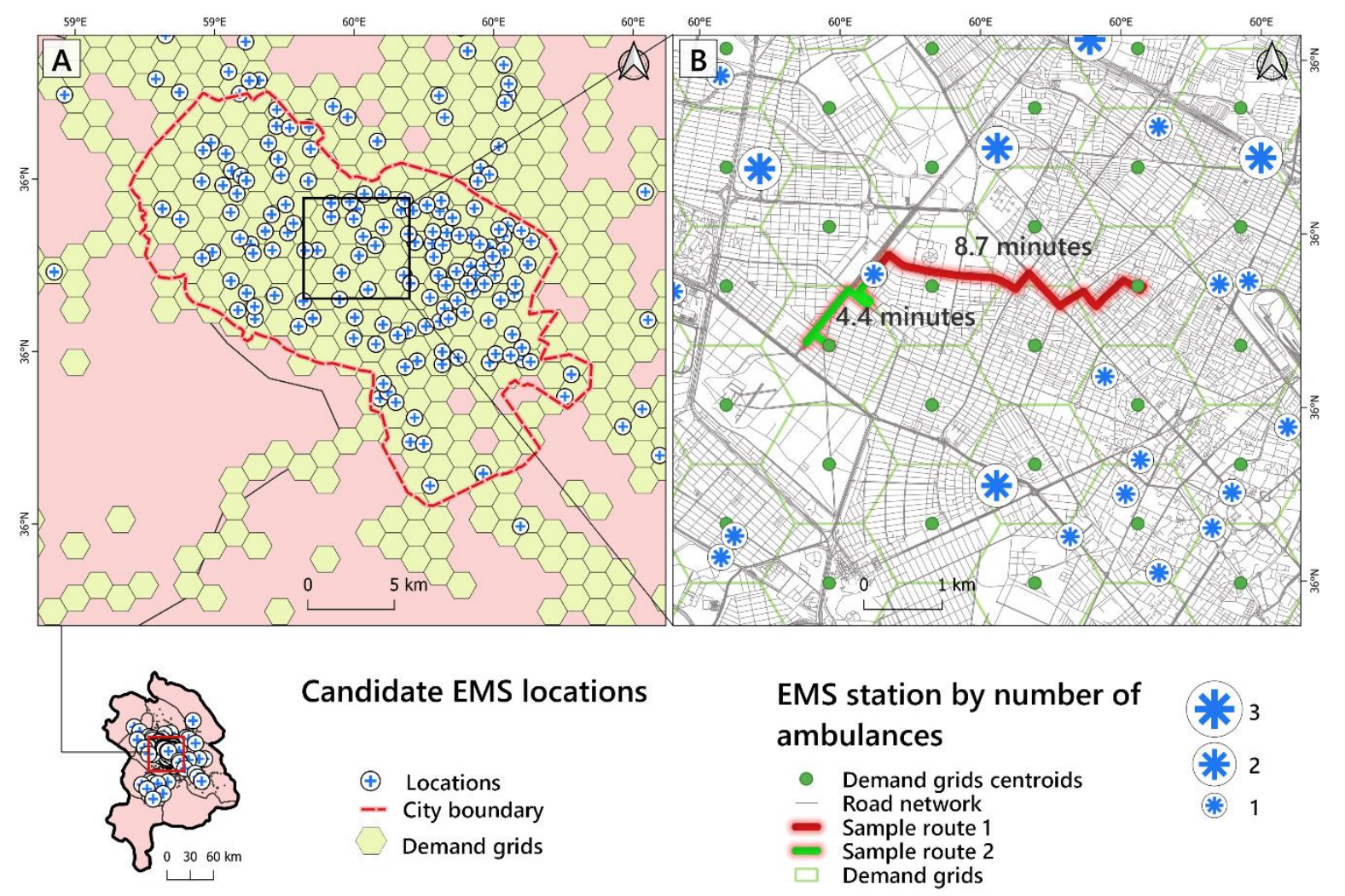

Figure 2: Required datasets for EMS location-allocation a) 233 candidate locations for new EMS stations b) road network dataset with two example routes

\subsection{Location-allocation model}

The basic model of capacitated MCLP was adopted from Haghani (30) and implemented with IBM ILOG CPLEX Optimization Studio v20.1 with Python 3 interface. CPLEX is a prescriptive analytics solution that enables rapid development and deployment of decision optimization models using mathematical and constraint programming (36). The basic capacitated MCLP model aims to maximize the weighted number of demand points covered in a standard threshold by considering a service capacity for each facility (or vehicle). In order to address the drawback of ignoring demands that cannot be reached within the service standard, we modified the formulation by adding a constraint ensuring that all demand points must have at least one ambulance vehicle within a travel distance. We define this distance threshold as maximum service distance. As urban and rural areas naturally have different spatial configurations of demands and EMS stations, we applied two levels of maximum service distances according to which the shorter distance was used for the urban demand points and the longer distance was used for the rural demand points. 


\subsubsection{Sets/Parameters}

$I_{u}=$ the set of urban demand points;

$I_{r}=$ the set of rural demand points;

$I=$ the set of all demand points $\{1, \ldots, i, \ldots, m\} ; I=\left\{I_{u} \cup I_{r}\right\}$

$J=$ the set of potential facility sites $\{1, \ldots, j, \ldots, n\}$;

$s=$ the service covering standard of the facility (minute);

$d_{i j}=$ the travel distance from potential facility site $j$ to demand point $i$;

$z_{i j}=\left\{\begin{array}{l}1 \text { if } d_{i j} \leq s \\ 0 \text { otherwise }\end{array}\right.$

$a_{i}=$ the amount of service demands at demand point $i$;

$p=$ the total number of ambulance vehicles to be located;

$c=$ the capacity of one ambulance vehicle (i.e., the maximum number of demands that a vehicle can cover);

$\mathrm{k}=$ the maximum number of ambulance vehicles that can be stationed on each potential facility site

$\mathrm{q}_{\mathrm{u}}=$ the maximum service distance within which each urban demand point has at least one ambulance;

$u_{i j}=\left\{\begin{array}{c}1 \text { if } d_{i j} \leq q_{u} \\ 0 \text { otherwise }\end{array}\right.$

$\mathrm{q}_{\mathrm{r}}=$ the maximum service distance within which each rural demand point has at least one ambulance;

$r_{i j}=\left\{\begin{array}{l}1 \text { if } d_{i j} \leq q_{r} \\ 0 \text { otherwise }\end{array}\right.$

$b_{j}=$ the number of existing ambulance vehicles stationed at potential facility site j;

\subsubsection{Decision variables}

$x_{j}=$ the number of ambulance vehicles newly added to potential facility site $j$; an EMS station is located on potential site $j$ when $b_{j}+x_{j}>0$;

$y_{i j}=$ the percentage of demands at demand point $i$ that is allocated to the facility on site $j$. 


\subsubsection{Model formulation}

Maximize $\quad \sum_{i \in I} \sum_{j \in J_{i}} a_{i} y_{i j}$

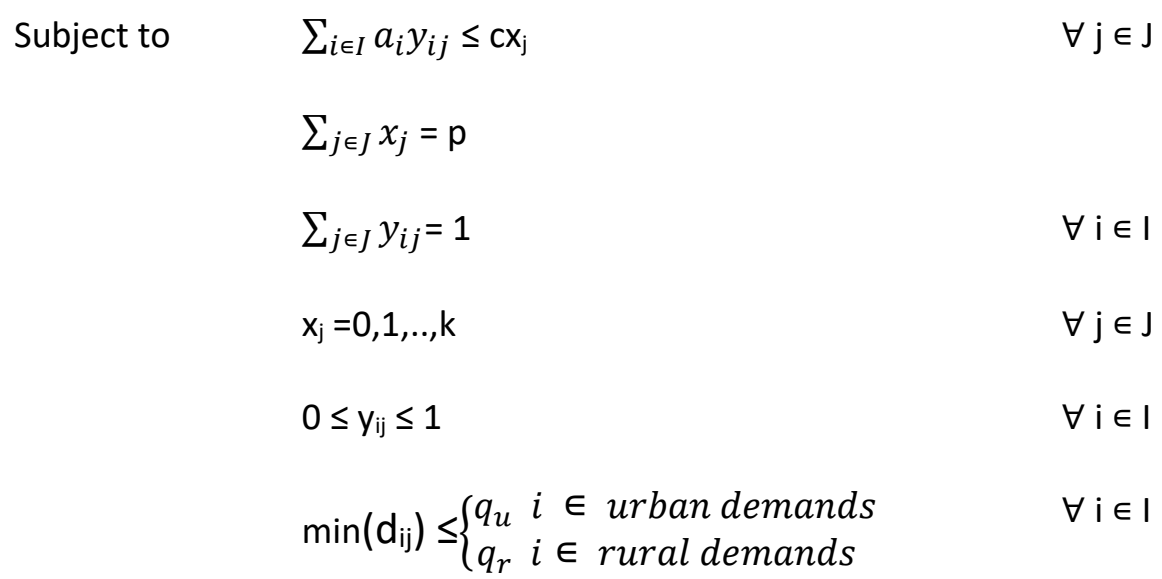

The objective function (1) seeks to maximize the number of covered demands. Constraint (2) ensure that total allocated demands to any facility cannot exceed the total capacity of ambulance vehicles stationed there. Constraint (3) specifies the total number of ambulance vehicles to be located. Constraint (4) ensures that the summation of demand ratios allocated to facilities should be one for any demand point. Constraint (5) restricts the discrete decision variable $\mathrm{x}_{\mathrm{j}}$, which ranges from 0 to $\mathrm{k}$. Constraint (6) restricts the continuous decision variable $y_{\mathrm{ij}}$, which ranges from 0 to 1 . The last two constraints (7) and (8) that we added in this study ensure that all of the demand points will have at least one ambulance vehicle within the travel time of $q_{u}$ and $q_{r}$ for urban and rural locations, respectively. It should be noted that the model in the current format is designed to optimally locate newly added vehicles while keeping the current distribution of the existing vehicles. However, when the existing vehicles at all stations are set to 0 (i.e., $b_{j}=0, \forall j \in J$ ), the model is converted to optimally locate all vehicles without any existing vehicles already located. The Python script related to this model is available in supplementary file 1.

\subsection{Scenarios}

The location-allocation problem was studied within the context of different scenarios: the current situation, named scenario 0 , and two main scenarios; 1 and 2 . The results of these scenarios were visualized using QGIS v. 3.20. 


\subsubsection{Scenario 0: Current situation}

This scenario aims to calculate the covered demand in the current situation without modifying the location of facilities or ambulances. Actually, this scenario does not include any optimization technique and serves as our study baseline for further comparisons. The parameters were set to calculate the coverage of 990 calls for service demand sites $(m)$ based on 94 existing ambulance vehicles ( $p$ ) in 74 existing stations ( $n$ ) using a 5-minute coverage standard (s). The ideal response time (time from call to arrival at the scene) is less than eight minutes based on World Health Organization recommendation (37). According to calculations from our recent study, the average preparation time (from call to starting the mission/journey) is almost 2.3 minutes (in press), and thus, we adjusted the specified coverage standard to a 5-minute travel time. The capacity of each ambulance vehicle (c) was set to 2,387, which is the average number of missions each ambulance vehicle was used during one year.

\subsubsection{Scenario 1: Relocation of existing vehicles}

Scenario 2 aims to maximize the covered demand by relocating the current ambulances with the existing stations (without adding any new facilities). This scenario inherits all the parameters from scenario 0 plus $\mathrm{k}=3, \mathrm{q}_{\mathrm{u}}=18 \mathrm{~min}$, and $\mathrm{q}_{\mathrm{r}}=48 \mathrm{~min}$. These values were set according to our current practice data according to which there is no station with more than three ambulances present, and all of the demand points are serviceable either in under 18 minutes within the urban area or under 48 minutes within the rural areas of Mashhad county. We forced the suggested model to preserve thresholds while maximizing the 5-minute coverage demands.

\subsubsection{Scenario 2: Allocation of new vehicles}

Scenario 2 aims at adding new ambulances to existing or newly proposed locations to maximize the coverage of demands. To do so, we added one to ten new ambulance vehicles, iteratively, in two ways: 1) keeping the current distribution of 94 existing vehicles from scenario 0 and optimally locating new vehicles ( $p=1$ to 10 ) to the current stations ( $n=74$ ) without adding any new station (scenario 2.1 ); 2 ) keeping the optimal distribution of 94 existing vehicles from scenario 1 and optimally locating the new 
vehicles ( $p=1$ to 10$)$ to the expanded list of facilities $(m=307)$ that include 74 existing stations and 233 candidate sites.

\section{Results}

\subsection{Scenario 1: Relocation of existing vehicles}

Table 1 shows the distribution of ambulance vehicles in Scenario 1 (relocation model) and compares it with Scenario 0 (the current situation). The relocation model took 12 stations of the service and placed the vehicles within the remaining stations as 37 stations with one vehicle, 18 stations with two vehicles, and seven stations with three vehicles. It is notable that using the relocation model, the proportion of covered demands increases from $69.36 \%$ to $75.19 \%$ in comparison to the current distribution. All of the stations with more than one vehicles were located in the urban area in both scenarios.

Table 1: Comparison of current distribution (scenario 0) vs. relocated distribution (scenario 1) of ambulance vehicles in Mashhad county, Iran

\begin{tabular}{|c|c|c|c|c|}
\hline \multicolumn{3}{|l|}{ Scenario } & $\begin{array}{l}0 \text { : Current } \\
\text { situation }\end{array}$ & $\begin{array}{l}1: \text { Relocation } \\
\text { model }\end{array}$ \\
\hline \multicolumn{3}{|c|}{ Total covered demands (\%) } & 155,617 (69.36\%) & $168,700(75.19 \%)$ \\
\hline \multicolumn{3}{|c|}{$\begin{array}{l}\text { Number of EMS stations (number of } \\
\text { ambulance vehicles) }\end{array}$} & $\begin{array}{l}55(1)+18(2)+ \\
1(3)\end{array}$ & $\begin{array}{l}12(0)+37(1)+ \\
18(2)+7(3)\end{array}$ \\
\hline Station ID & location & (longitude, latitude) & No. of vehicles & No. of vehicles \\
\hline 1 & Urban & $(59.5806,36.2919)$ & 2 & 2 \\
\hline 2 & Urban & $(59.6258,36.2861)$ & 2 & 0 \\
\hline 3 & Urban & $(59.5819,36.3308)$ & 2 & 3 \\
\hline 4 & Urban & $(59.5103,36.3300)$ & 3 & 3 \\
\hline 5 & Urban & $(59.6428,36.3008)$ & 2 & 3 \\
\hline 6 & Urban & $(59.4944,36.3650)$ & 1 & 1 \\
\hline 7 & Urban & $(59.5406,36.2842)$ & 1 & 1 \\
\hline 8 & Urban & $(59.6036,36.2478)$ & 2 & 3 \\
\hline 9 & Urban & (59.5481,36.3292) & 2 & 1 \\
\hline 10 & Urban & $(59.6578,36.3150)$ & 1 & 2 \\
\hline 11 & Urban & $(59.6131,36.3144)$ & 1 & 2 \\
\hline 12 & Urban & $(59.6628,36.2708)$ & 2 & 1 \\
\hline 13 & Urban & $(59.5911,36.2747)$ & 1 & 0 \\
\hline 14 & Urban & $(59.5956,36.3431)$ & 2 & 1 \\
\hline 15 & Urban & $(59.5150,36.3594)$ & 1 & 2 \\
\hline 16 & Urban & $(59.6111,36.2864)$ & 1 & 3 \\
\hline 17 & Urban & $(59.6486,36.3300)$ & 1 & 1 \\
\hline
\end{tabular}




\begin{tabular}{|c|c|c|c|c|}
\hline 18 & Urban & $(59.5908,36.2858)$ & 1 & 2 \\
\hline 19 & Urban & $(59.5964,36.3042)$ & 1 & 1 \\
\hline 20 & Urban & $(59.6222,36.2978)$ & 1 & 0 \\
\hline 21 & Urban & $(59.6033,36.2814)$ & 1 & 0 \\
\hline 22 & Urban & $(59.6519,36.2642)$ & 1 & 1 \\
\hline 23 & Urban & $(59.5172,36.3025)$ & 2 & 2 \\
\hline 24 & Urban & $(59.6072,36.2700)$ & 2 & 1 \\
\hline 25 & Urban & $(59.5639,36.3167)$ & 1 & 1 \\
\hline 26 & Urban & $(59.6344,36.2683)$ & 2 & 2 \\
\hline 27 & Urban & $(59.6172,36.3147)$ & 1 & 2 \\
\hline 28 & Urban & $(59.6256,36.2197)$ & 2 & 0 \\
\hline 29 & Urban & $(59.5431,36.3725)$ & 2 & 1 \\
\hline 30 & Urban & $(59.6194,36.3289)$ & 2 & 2 \\
\hline 31 & Urban & $(59.4975,36.3150)$ & 2 & 3 \\
\hline 32 & Urban & $(59.6214,36.2678)$ & 1 & 2 \\
\hline 33 & Urban & $(59.5917,36.2611)$ & 1 & 1 \\
\hline 34 & Urban & $(59.6739,36.2997)$ & 1 & 2 \\
\hline 35 & Urban & $(59.5989,36.2906)$ & 1 & 2 \\
\hline 36 & Urban & $(59.6519,36.1139)$ & 1 & 0 \\
\hline 37 & Urban & $(59.5431,36.2869)$ & 1 & 1 \\
\hline 38 & Urban & $(59.4733,36.3756)$ & 1 & 1 \\
\hline 39 & Urban & $(59.6789,36.3147)$ & 2 & 0 \\
\hline 40 & Urban & $(59.5383,36.3583)$ & 1 & 1 \\
\hline 41 & Urban & $(59.4681,36.3642)$ & 1 & 1 \\
\hline 42 & Urban & $(59.4981,36.3217)$ & 1 & 1 \\
\hline 43 & Urban & $(59.6011,36.2944)$ & 1 & 2 \\
\hline 44 & Urban & $(59.5428,36.34)$ & 1 & 1 \\
\hline 45 & Urban & $(59.6247,36.3492)$ & 1 & 1 \\
\hline 46 & Urban & $(59.4858,36.3606)$ & 1 & 0 \\
\hline 47 & Urban & $(59.6414,36.3156)$ & 1 & 2 \\
\hline 48 & Urban & $(59.4767,36.3364)$ & 1 & 2 \\
\hline 49 & Urban & $(59.6781,36.3214)$ & 2 & 2 \\
\hline 50 & Urban & $(59.5353,36.3153)$ & 1 & 1 \\
\hline 51 & Urban & $(59.5125,36.3611)$ & 1 & 1 \\
\hline 52 & Urban & $(59.605,36.3328)$ & 1 & 2 \\
\hline 53 & Urban & $(59.6417,36.2669)$ & 1 & 0 \\
\hline 54 & Urban & $(59.5083,36.3964)$ & 1 & 3 \\
\hline 55 & Rural & $(59.7167,36.4483)$ & 1 & 1 \\
\hline 56 & Urban & $(59.6425,36.2272)$ & 1 & 0 \\
\hline 57 & Urban & $(59.6644,36.2133)$ & 1 & 1 \\
\hline 58 & Rural & $(59.7283,36.2372)$ & 1 & 1 \\
\hline 59 & Rural & $(59.5136,36.4844)$ & 1 & 1 \\
\hline 60 & Rural & $(59.6725,36.4328)$ & 1 & 1 \\
\hline 61 & Rural & $(59.6501,36.4633)$ & 1 & 0 \\
\hline 62 & Urban & $(59.6939,36.2753)$ & 1 & 1 \\
\hline 63 & Rural & $(59.4892,36.4189)$ & 2 & 1 \\
\hline 64 & Urban & $(59.5172,36.37)$ & 1 & 1 \\
\hline 65 & Urban & $(5961404,362904)$ & 1 & 2 \\
\hline 66 & Rural & $(59.8375,36.5856)$ & 1 & 1 \\
\hline 67 & Rural & $(59.5836,36.9889)$ & 1 & 1 \\
\hline 68 & Rural & $(59.9603,36.0783)$ & 1 & 1 \\
\hline 69 & Rural & $(59.3911,36.7858)$ & 1 & 1 \\
\hline
\end{tabular}




\begin{tabular}{|l|c|c|c|c|}
\hline 70 & Rural & $(59.7367,36.0947)$ & 1 & 1 \\
\hline 71 & Rural & $(59.3581,36.985)$ & 1 & 1 \\
\hline 72 & Rural & $(59.4225,36.8886)$ & 1 & 1 \\
\hline 73 & Rural & $(59.1278,36.2586)$ & 1 & 0 \\
\hline 74 & Rural & $(59.6694,36.6539)$ & 1 & 1 \\
\hline
\end{tabular}

To better understand the pattern of relocation by Scenario 1, we visualized the proposed changes in a map as shown in Figure 3. The changes in the number of ambulances within each station ranged from -2 to 2 vehicles. The most variation was seen in the eastern part of the city.

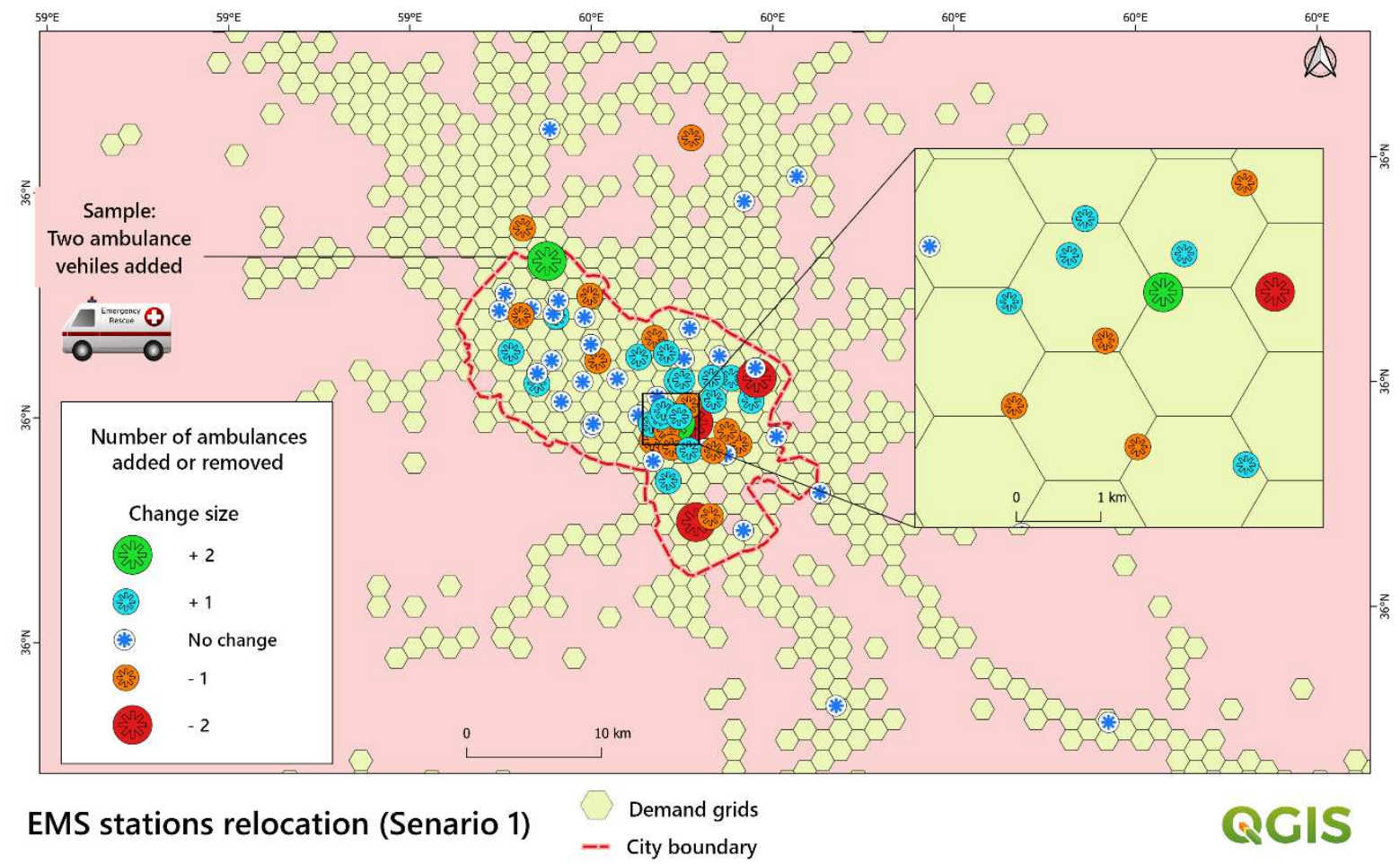

Figure 3: Proposed relocation of ambulance vehicles based on Scenario 1

\subsection{Scenario 2: Allocation of new vehicles}

Table 2 shows the optimum locations of new ambulances according to Scenarios 2.1 and 2.2. Most of the selected locations in Scenario 2.2 are among new candidate locations (Note, the station IDs of 75 and higher are new stations). Indeed, only stations 5 and 65 received new ambulance vehicles among the existing stations. The difference in the amount of demand covered by the two versions of the scenario is noticeable (see also Figure 4). 


\begin{tabular}{|l|ll|ll|}
\hline & \multicolumn{3}{|l|}{$\begin{array}{l}\text { Scenario 2.1: Added to existing distribution } \\
\text { without adding a new facility }\end{array}$} & $\begin{array}{l}\text { Scenario 2.2: Added to relocated distribution } \\
\text { with adding new facilities }\end{array}$ \\
\hline $\begin{array}{l}\text { No. of } \\
\text { new } \\
\text { vehicles }\end{array}$ & $\begin{array}{l}\text { Station IDs of added } \\
\text { vehicles }\end{array}$ & $\begin{array}{l}\text { Total covered } \\
\text { demands (\%) }\end{array}$ & $\begin{array}{l}\text { Station IDs of added } \\
\text { vehicles }\end{array}$ & $\begin{array}{l}\text { Total covered } \\
\text { demands (\%) }\end{array}$ \\
\hline 0 & - & $155,617(69.36)$ & - & $168,700(75.19)$ \\
\hline 1 & 11 & $158,004(70.43)$ & 75 & $171,087(76.26)$ \\
\hline 2 & 11,65 & $160,391(71.49)$ & 153,195 & $173,474(77.32)$ \\
\hline 3 & $10,11,65$ & $162,355(72.37)$ & $65,182,283$ & $175,861(78.39)$ \\
\hline 4 & $10,11,24,65$ & $164,055(73.12)$ & $75,80,93,93$ & $178,248(79.45)$ \\
\hline 5 & $10,11,16,21,65$ & $165,694(73.85)$ & $75,80,91,91,91$ & $180,635(80.51)$ \\
\hline 6 & $10,11,24,31,52,65$ & $167,249(74.55)$ & $75,80,91,91,91,102$ & $182,974(81.56)$ \\
\hline 7 & $10,11,24,31,48,52$, & $168,270(75.00)$ & $5,65,75,80,92,181$, & $184,960(82.44)$ \\
& 65 & & 283 & $186,884(83.30)$ \\
\hline 8 & $3,10,11,24,31,48$, & $168,492(75.10)$ & $5,65,75,80,91,92$, & $188,591(84.06)$ \\
\hline 9 & 52,65 & & 181,283 & $190,257(84.80)$ \\
\hline 10 & $3,10,11,16,19,31$, & $168,606(75.15)$ & $5,65,75,80,91,92$, & \\
\hline
\end{tabular}

Figure 4 demonstrates the trend of demand coverage for scenario 2 in a better way. The proportion of covered demand for Scenario 2.1 was about $69 \%$ in the initial specification (equal to Scenario 0). The increasing trend remains almost steady at $75 \%$ after adding six vehicles. In contrast, Scenario 2.2 shows a steady increase from the initial point of $75 \%$ (equal to Scenario 1 ) rising to almost $85 \%$ after adding ten new vehicles.

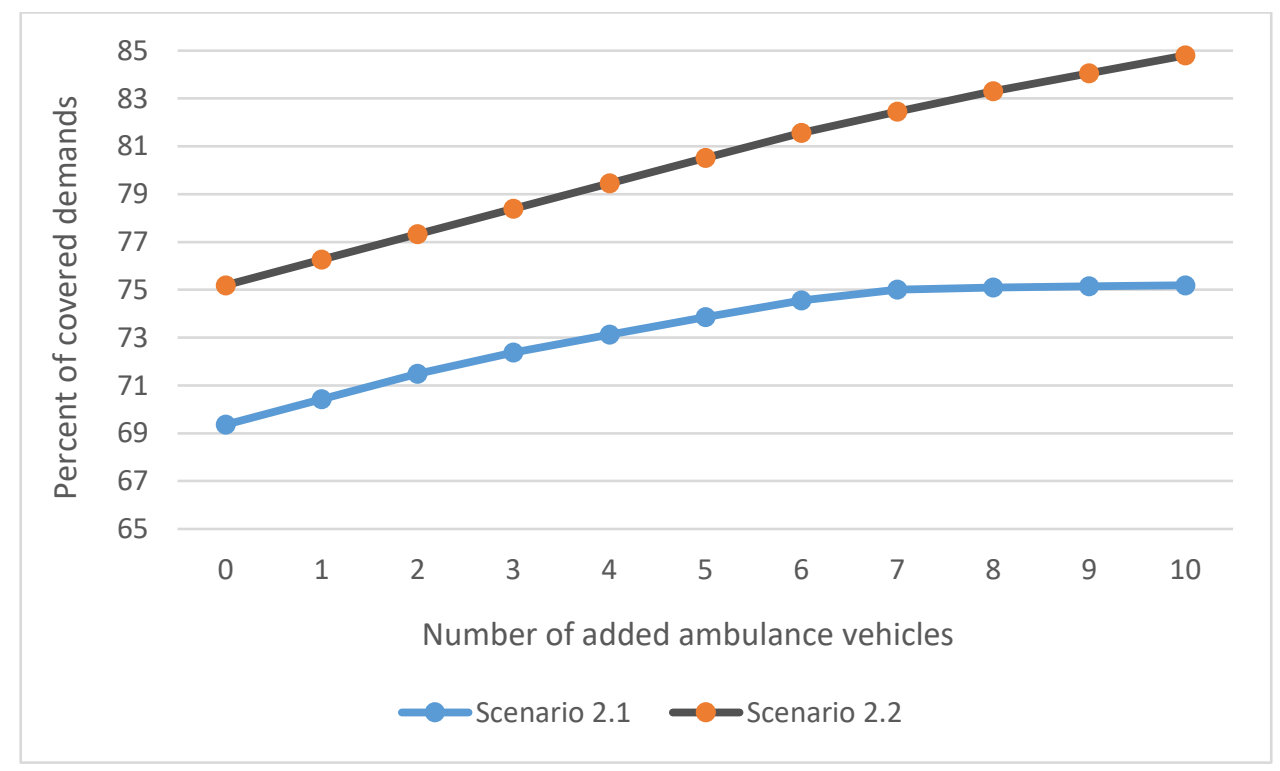

Figure 4: Percent of covered demands in scenario 2.1 vs. scenario 2.2 for each added ambulance vehicle 
The proposed spatial locations of the new ambulance vehicles added by Scenarios 2.1 and 2.2 are shown in Figure 5 and Error! Reference source not found., respectively. All of the allocated new ambulances by Scenario 2.1 are related to the urban stations. The first five vehicles were added to the eastern part of the city, but additional vehicles were added to cover the western part of the city as well. Each station received not more than one vehicle in this scenario.

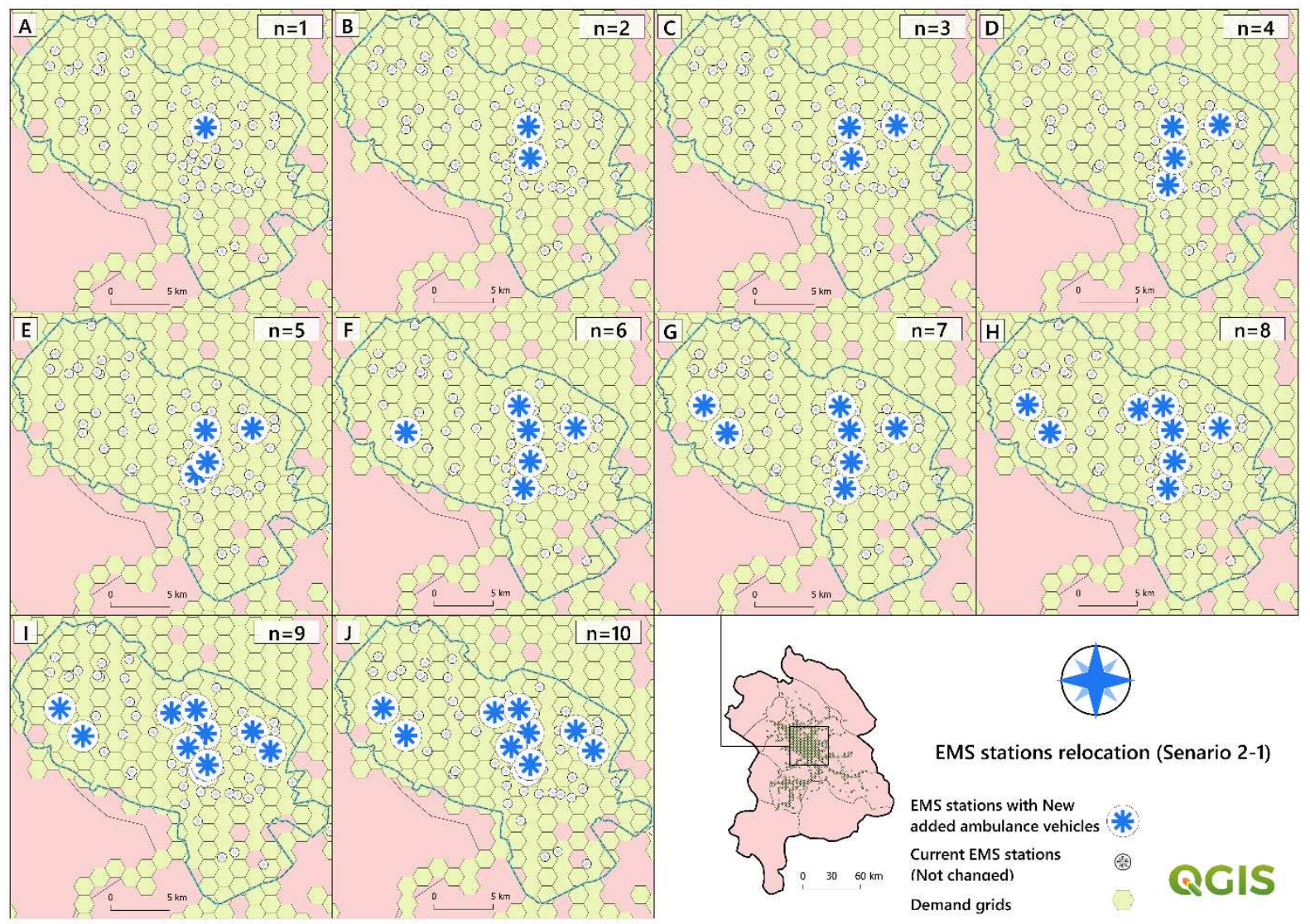

Figure 5: Visualized depiction of scenario 2.1 results: adding 1 to 10 new ambulance vehicles to the existing distribution without adding any new facility

In scenario 2.2, once again, most of the vehicles were assigned to the stations in urban areas (Figure 6). Arguably, there is more of a balance between east and west of the city in the allocation of vehicles. After adding seven vehicles, one location outside the city (a north-eastern suburb) received one ambulance (Figure 6, G to H). This station was added in the third (Figure 6, C) but did not reappear as a permanent new site until a seventh vehicle was added. In Scenario 2.2, up to three vehicles were added to a single facility location. 


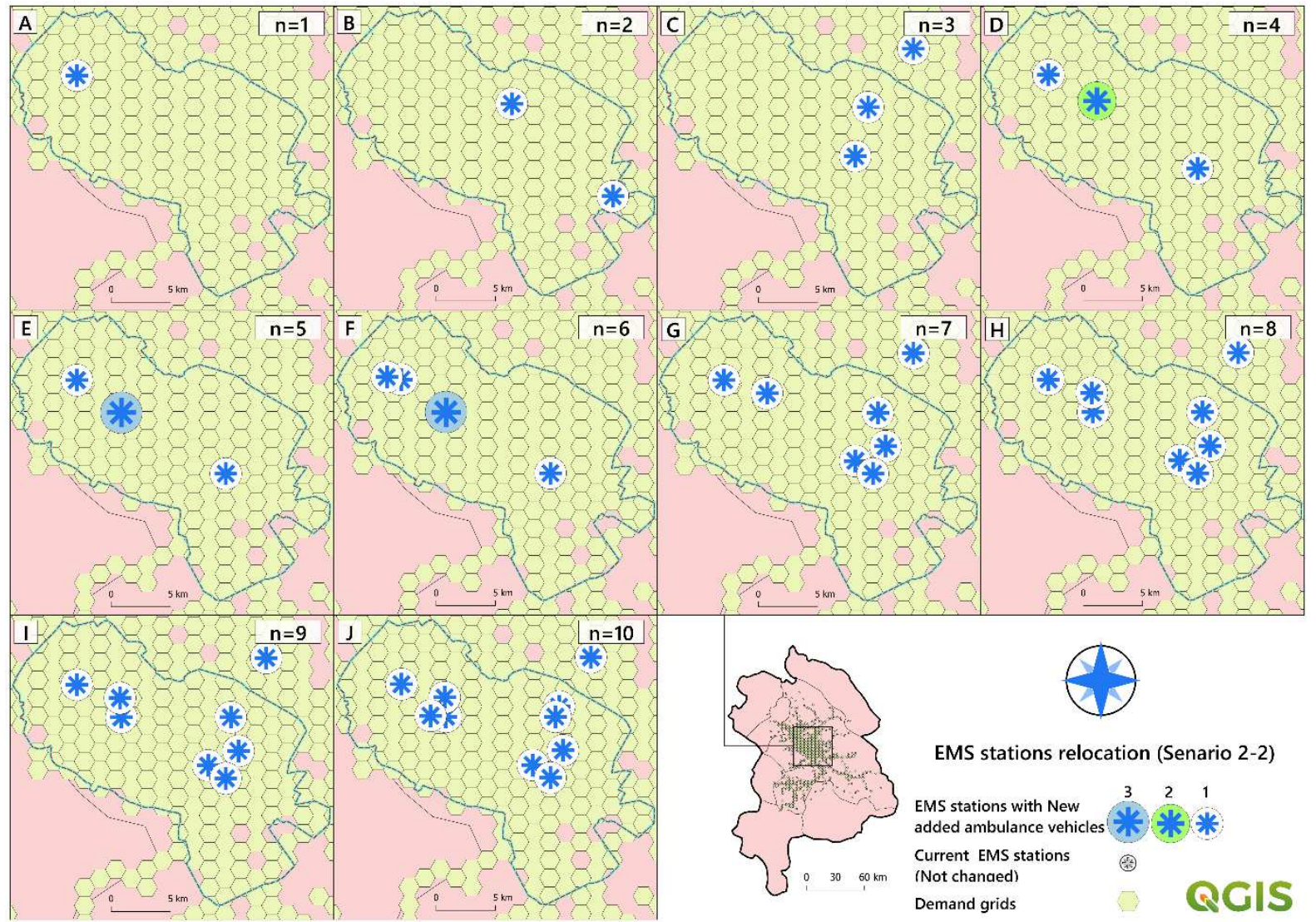

Figure 6: Visualized depiction of scenario 2.2 results: adding 1 to 10 new ambulance vehicles to relocated distribution while allowing new facilities (from candidate locations) to be added

\section{Discussion}

Optimizing the location of ambulance vehicles has the potential to improve EMS service delivery. Response time is a crucial determinant of patients' survival in emergency events. Our previous study showed that the average response time is 10.1 and 12.2 minutes for urban and rural events in the county of Mashhad (in press), which exceed the 8-minute universal standard (37). Part of this total response time is related to the preparation time in the dispatch center and the EMS station facility. Therefore, the allocation of ambulances vehicles able to reach potential emergency cases within a 5minutes catchment area is of great importance for final care outcome. In our study, the proportion of demands within the 5-minute coverage standard increased from $69 \%$ in the current situation to $75 \%$, using our proposed relocation model based on existing vehicles. Our suggested allocation models also revealed that, under different scenarios, this figure could rise to almost $84 \%$ by adding up to ten vehicles. 
In the first stage of our method, we used GIS tools to extract datasets in need: facilities, demands, and cost matrix. In addition to the existing stations, we used 233 candidate locations for establishing potentially new stations. Most of the studies in the location-allocation context used residential population and administrative divisions to obtain demand points. The residential population does not consider travelers' population and residents' characteristics such as age distribution and comorbidities in weighting the demand points. Moreover, for studies on a bigger scale than a city, there is no population data for roads and remote areas, which are potential areas for road traffic emergencies (7). To address the above limitations, we preferred to use EMS call data (and a grid network covering the study area) as the representative data of all year-around fluctuation of population-based demands. Although the overall pattern of calls may change every year, the geographical distribution is likely to be mostly stable, and as such the year of call data leveraged in this study is a useful proxy for actual demand. Online web mapping databases like OpenStreetMap enabled us to calculate network distances from facilities to demands which is a much better proxy of real travel time than using the Euclidean distance (38).

Although the development of location-allocation theories was independent of GIS development, commercial GIS software (e.g., ArcGIS) have recently started to provide functionalities to solve location problems. For example, ArcGIS provides toolboxes to solve six different types of locationallocation problems consisting of minimize impedance, maximize coverage, minimize facilities, maximize attendance, maximize market share, and target market share (39). However, these toolboxes provide mostly basic functions and are not flexible enough to catch the characteristics of various real-world problems. For example, in the maximize capacitated coverage problem type, which is almost similar to the model we used in this study, a demand node can only receive service from one facility. If the demand weight exceeds the service capacity of facilities, the demand point would not be covered in any way (39). In 2002, Church published a review study on GIS application in locationallocation domain (40). Church mentioned the capabilities of GIS such as storage, retrieval, analysis, visualization, and mapping the geospatial data and stated that it is hard to believe that GIS would play just a supporting role in location science in the future. After almost two decades, GIS perhaps still 
plays a supporting role in location-allocation literature and only few studies have employed tools embedded within a GIS to solve location-allocation optimization models (41-43).

Optimization models are mathematical models that include functions that represent objectives and constraints for the system being modeled (44). CPLEX is a popular optimization solver which is able to connect to scripting languages like Python, MATLAB, or R (36). Using mathematical modeling, we were able to modify the capacitated MCLP in a way to fit our study context. Modifying the model by adding the new constraints was necessary as otherwise the relocation model would remove some of the stations in rural areas that deliver service to a lower number of calls for service.

The results of Scenario 1 revealed that how much a proper relocation plan could potentially improve the final outcome of an EMS system. Such improvement was equal to adding ten vehicles to the existing stations. Furthermore, the relocation model allowed the evacuation of 12 out of 74 stations and proposed a new efficient while effective distribution resulting in better service accessibility. Most of the proposed changes in the station capacities by Scenario 1 were related to the eastern part of the city, near downtown and the holy shrine area (Figure 3). This area, with a large number of proposed changes, overlaps with the hotspot cluster of EMS requests we identified earlier using the spatiotemporal scan statistics method (in press). Downtown Mashhad is an area with a high concentration of hotels, residential complexes, and shopping malls. Changes in ambulance deployment in this area show greater effects in the coverage performance measure.

Comparing Scenarios 2.1 and 2.2 shows the importance of allowing the improvement studies to be open for considering new potential locations. Establishing new stations based on optimal locations could cover demand points more efficiently. In Scenario 2.1, the performance measure becomes saturated after adding six vehicles as there are few uncovered demands left within the catchment of existing stations. But, adding stations in optimum locations expands opportunities for better demand coverage.

There are some limitations in this study. First, we used one-year call data as a proxy of demand points. Our analytics would have been more accurate or realistic if we had data for multiple years. For instance, with the emergence of Covid-19, the pattern of EMS requests may have changed as 
compared to our study period. Second, the severity of reported medical emergencies in EMS calls was not recorded in the database. It is evident that most severe cases have priority for EMS service delivery, and if available, we would be able to weigh our demand points according to the level of severity. Finally, the issue of modifiable areal unit problem (45) remains inherent to the studies that focus on aggregated spatial data. Changing the demand polygons, making them bigger or smaller, could affect the results of the location-allocation analysis. In our work, to partially address the issue, we defined polygons as equal to the average size of neighborhoods within the Mashhad county area.

\section{Conclusions}

Integrating GIS and optimization modeling has a great potential to improve the accessibility and equity in distribution of EMS resources. The modified version of capacitated MCLP model we proposed and evaluated in this study is generalizable to any resource management problem where the aim is to maintain an acceptable service coverage level for all demands while maximizing the coverage as much as possible. We strongly believe that our model also has the potential to be used in prospective health service planning according to current to future patterns of service demands, especially when the equity of service being delivered is essential.

\section{Declarations}

\subsection{Ethics approval and consent to participate}

This study was approved by ethic committee of Mashhad University of Medical Sciences (number: IR.MUMS.MEDICAL.REC.1397.687) and caller's identity were anonymous for privacy issues.

\subsection{Consent for publication}

Not applicable

\subsection{Availability of data and materials}

Not applicable

\subsection{Competing interests}

The authors declare that there is no conflict of interest 


\subsection{Funding}

This project is funded by Mashhad University of Medical Sciences (grant number: 970861)

\subsection{Authors' contributions}

S.A.M. and M.T. designed the study. S.M. geocoded and pre-processed the data. B.K. and A.M. conducted the spatial analysis. P.Y. and S.H. conducted and interpreted the mathematical modelling. S.H. drafted the manuscript. M.T. and S.A.M. revised the text critically. The authors read and approved the final manuscript.

\subsection{Acknowledgments}

Special thanks are extended to the staff of EMS center of Mashhad university of Medical science who provided the information needed for this study

\section{References}

1. Aringhieri R, Bruni ME, Khodaparasti S, van Essen JT. Emergency medical services and beyond: Addressing new challenges through a wide literature review. Computers \& Operations Research. 2017;78:349-68.

2. Martinez R. New vision for the role of emergency medical services. Annals of emergency medicine. 1998;32(5):594-9.

3. Ong ME, Ng FS, Overton J, Yap S, Andresen D, Yong DK, et al. Geographic-time distribution of ambulance calls in Singapore: utility of geographic information system in ambulance deployment (CARE 3). Ann Acad Med Singap. 2009;38(3):184-91.

4. Haddadi M, Sarvar M, Soori H, Ainy E. The Pattern of Pre-hospital Medical Service Delivery in Iran; a Cross Sectional Study. Emerg (Tehran). 2017;5(1):e57.

5. Sasaki S, Comber AJ, Suzuki H, Brunsdon C. Using genetic algorithms to optimise current and future health planning - the example of ambulance locations. Int J Health Geogr. 2010;9(1):4.

6. Nykiforuk Cl, Flaman LM. Geographic information systems (GIS) for Health Promotion and Public Health: a review. Health Promot Pract. 2011;12(1):63-73.

7. Tabari P, Shabanikiya H, Bagheri N, Bergquist R, Hashtarkhani S, Kiani F, et al. Paediatric, pedestrian road traffic injuries in the city of Mashhad in north-eastern Iran 2015-2019: a data note. BMC Res Notes. 2020;13(1):363.

8. Kiani B, Bagheri N, Tara A, Hoseini B, Hashtarkhani S, Tara M. Comparing potential spatial access with self-reported travel times and cost analysis to haemodialysis facilities in North-eastern Iran. Geospat Health. 2018;13(2).

9. Hashtarkhani S, Kiani B, Bergquist R, Bagheri N, VafaeiNejad R, Tara M. An age-integrated approach to improve measurement of potential spatial accessibility to emergency medical services for urban areas. Int J Health Plann Manage. 2020;35(3):788-98.

10. Azimi A, Bagheri N, Mostafavi SM, Furst MA, Hashtarkhani S, Amin FH, et al. Spatial-time analysis of cardiovascular emergency medical requests: enlightening policy and practice. BMC Public Health. 2021;21(1):7.

11. Thi Nguyen N-H. Quantitative analysis of ambulance location-allocation and ambulance state prediction: Linköping University Electronic Press; 2015.

12. Pasha I. Ambulance management system using GIS. Universitetsbibliotek; 2006. 
13. Chuvieco E. Integration of linear programming and GIS for land-use modelling. International Journal of Geographical Information Science. 1993;7(1):71-83.

14. Vafaeinejad A, Bolouri S, Alesheikh AA, Panahi M, Lee C-W. The Capacitated LocationAllocation Problem Using the VAOMP (Vector Assignment Ordered Median Problem) Unified Approach in GIS (Geospatial Information Systam). Applied Sciences. 2020;10(23):8505.

15. Sher $M$, Adler $N$, Hakkert A, editors. The police vehicle location-allocation problem. International Conference on Industrial Logistics, ISRAEL; 2008: Citeseer.

16. Daskin MS, Maass KL. The p-median problem. Location science: Springer; 2015. p. 21-45.

17. Farahani RZ, Asgari N, Heidari N, Hosseininia M, Goh M. Covering problems in facility location: A review. Computers \& Industrial Engineering. 2012;62(1):368-407.

18. Toregas C, Swain R, ReVelle C, Bergman L. The location of emergency service facilities. Operations research. 1971;19(6):1363-73.

19. Church $\mathrm{R}$, ReVelle $\mathrm{C}$, editors. The maximal covering location problem. Papers of the regional science association; 1974: Springer-Verlag.

20. Brotcorne L, Laporte G, Semet F. Ambulance location and relocation models. European journal of operational research. 2003;147(3):451-63.

21. Daskin MS. A maximum expected covering location model: formulation, properties and heuristic solution. Transportation science. 1983;17(1):48-70.

22. Marianov V, Serra D. Probabilistic, maximal covering location-allocation models forcongested systems. Journal of Regional Science. 1998;38(3):401-24.

23. de Assis Corrêa F, Lorena LAN, Ribeiro GM. A decomposition approach for the probabilistic maximal covering location-allocation problem. Computers \& Operations Research. 2009;36(10):272939.

24. Galvão RD, Chiyoshi FY, Morabito R. Towards unified formulations and extensions of two classical probabilistic location models. Computers \& Operations Research. 2005;32(1):15-33.

25. Current JR, Storbeck JE. Capacitated covering models. Environment and planning B: planning and Design. 1988;15(2):153-63.

26. Liao K, Guo D. A clustering-based approach to the capacitated facility location problem 1. Transactions in GIS. 2008;12(3):323-39.

27. Yin P, Mu L. Modular capacitated maximal covering location problem for the optimal siting of emergency vehicles. Applied Geography. 2012;34:247-54.

28. Gazani M, Niaki S. The capacitated maximal covering location problem with heterogeneous facilities and vehicles and different setup costs: An effective heuristic approach. International Journal of Industrial Engineering Computations. 2021;12(1):79-90.

29. Cazabat G, Belu MG, Popa I, Paraschiv DM. Models and practice of retail location on the romanian market. Amfiteatru Economic. 2017;19(45):493.

30. Haghani A. Capacitated maximum covering location models: Formulations and solution procedures. Journal of Advanced Transportation. 1996;30(3):101-36.

31. Iran SCo. Census 2016 Results 2016 [Available from: https://www.amar.org.ir/english/Population-and-Housing-Censuses.

32. Kafashpor A, Ghasempour Ganji SF, Sadeghian S, Johnson LW. Perception of tourism development and subjective happiness of residents in Mashhad, Iran. Asia Pacific Journal of Tourism Research. 2018;23(6):521-31.

33. Schietzelt TH, Densham PJ. Location-allocation in GIS. Advanced spatial analysis: the CASA book of GIS. 2003;345.

34. OpenStreetMap database 2021 [Available from: www.openstreetmap.org.

35. OpenStreetMap. OSM tags for routing 2021 [Available from:

https://wiki.openstreetmap.org/wiki/OSM tags for routing/Maxspeed.

36. Manual CUs. Ibm ilog cplex optimization studio. Version. 1987;12:1987-2018.

37. Pons PT, Markovchick VJ. Eight minutes or less: does the ambulance response time guideline impact trauma patient outcome? The Journal of emergency medicine. 2002;23(1):43-8.

38. Buczkowska S, Coulombel N, de Lapparent M. A comparison of euclidean distance, travel times, and network distances in location choice mixture models. Networks and spatial economics. 2019;19(4):1215-48.

39. ESRI. Location-allocation analysis 2021 [Available from: https://desktop.arcgis.com/en/arcmap/latest/extensions/network-analyst/location-allocation.htm. 
40. Church RL. Geographical information systems and location science. Computers \& Operations Research. 2002;29(6):541-62.

41. Mindahun W, Asefa B. Location allocation analysis for urban public services using GIS techniques: A case of primary schools in Yeka sub-city, Addis Ababa, Ethiopia. Am J Geogr Inf Syst. 2019;8:26-38.

42. Alifi MR, Hayati $H$, Supangkat $S H$, editors. Optimization of school network using locationallocation analysis: Case study: Bandung, Indonesia. 2017 IEEE Region 10 Symposium (TENSYMP); 2017: IEEE.

43. Ferguson WJ, Kemp K, Kost G. Using a geographic information system to enhance patient access to point-of-care diagnostics in a limited-resource setting. Int J Health Geogr. 2016;15(1):1-12. 44. Neittaanmäki P, Repin S, Tuovinen T. Mathematical modeling and optimization of complex structures: Springer; 2016.

45. Openshaw S. The modifiable areal unit problem. Quantitative geography: A British view. 1981:60-9. 


\section{Supplementary Files}

This is a list of supplementary files associated with this preprint. Click to download.

- SuplementraryMaterial1.txt 